\title{
Bittering agents in the prevention of accidental poisoning: children's reactions to Denatonium Benzoate (Bitrex)
}

\author{
J. R. SIBERT \& N. FRUDE
}

Department of Child Health, University of Wales College of Medicine, Llandough Hospital and School of Psychology, University of Wales College of Cardiff, Wales

\section{SUMMARY}

The responses of young children to Denatonium Benzoate (Bitrex) were observed, in order to assess the potential of this bittering agent in the prevention of accidental poisoning. Thirty-three children aged 17-36 months were offered orange juice containing Bitrex (in a concentration of 10 parts per million). Of the 30 children who took some of this juice, only seven were willing to take more than $10 \mathrm{gm}$. A variety of negative verbal and non-verbal responses were noted. It is suggested that the highly unpalatable nature of Bitrex makes this compound a useful additive that could well prevent accidental poisoning from household products of mild to moderate toxicity.

\section{INTRODUCTION}

Some household products such as cleaning fluids and white spirit are dangerous when ingested by young children, and yet it has been estimated that some 36000 such accidental poisonings involving such substances occur each year within the U.K. A survey for the drug manufacturers Macfarlan Smith suggests that about 1 in 15 households with children have experienced at least one instance in which a child has ingested a toxic substance (Macfarlan Smith, 1988), and approximately one child in 600 is admitted to hospital each year as a result of accidental poisoning (Craft et al., 1984). Some of the measures introduced to prevent accidental selfpoisoning are of a health educational nature and thus have limited applicability to young children. Others involve making toxic substances inaccessible, and child resistant closures have had a major impact on the prevention of accidental child

Correspondence: Dr J. Sibert, Consultant Paediatrician, Llandough Hospital, Penarth, South Glamırgan CF6 1XX, Wales, U.K. 
poisoning both in the U.S. and in Europe (Scherz, 1970; Clarke and Walton, 1979; Sibert et al., 1977). Such strategies cannot prevent all cases of accidental poisoning because household products such as paint thinners, white spirit and turpentine are commonly poured into containers other than those in which they are supplied.ळ Neither can they prevent Kerosene poisoning, a major problem in the third world, and probably the most common cause of accidental poisoning fatalities in children $\stackrel{?}{?}$ worldwide.

Another possible means of reducing the magnitude of the problem would be to add provide a harmless additive which would make dangerous household liquids $\overline{0}$ taste so bitter or so foul that children would not continue to ingest the harmfulo material. Tasting such a preparation would probably lead a child to immediately $\vec{\theta}$ stop ingesting and to avoid any further sampling. Denatonium benzoate, benzyldiethyl (2:6-xylylcarbamoyl methyl) ammonium benzoate (Bitrex) may be an 'ideal $\vec{\omega}$ compound' of this type. It is non-toxic; chemically stable, and related to Lignocaine® (Macfarlan Smith, 1988). It is also the most bitter substance known, very dilute solutions (of the order of 100 parts or less per billion) being experienced as bitter.:Even in very dilute solutions the taste is not masked by the tastes of household chemicals. A considerable body of research now testifies to the non-toxicity of ${ }_{-}$ Bitrex, to its bitterness and its powerful and aversive taste. The question of how 3 young children respond when they taste a liquid containing Bitrex, however, has $\stackrel{\$}{\sim}$ not been adequately explored. The study to be reported is an investigation of how young children behave after having ingested orange juice to which a standard $₫$ solution of Bitrex has been added.

\section{SUBJECTS}

Thirty-three children (18 boys and 15 girls) between the ages of $17-36$ months $\overrightarrow{\vec{*}}$ (mean age $=27$ months, s.d. 5.52 months) were tested in the video laboratory of 3 the Department of Psychology, University College, Cardiff. Their mothers were present with them throughout the study. The mother-child couples were recruited through local nurseries and pre-school groups, and the mothers were informed in 3 advance of the nature and purpose of the study.

\section{METHOD}

The mothers and children attended the Department and waited in a large room supplied with toys, games and video cartoons. The mothers had previously been given a brief written introduction to the study, but had been asked not to tell the child what to expect. Each mother-child couple was taken (one 'couple' at a time) into the 'video studio', a pleasantly furnished room without technical equipment. The room included a one-way screen through which the proceedings were video- $\bar{\Phi}$ taped. The female experimenter first attempted to engage the child, using drawing? activity, or Lego play. When it was judged that the child was relaxed, the exper- 
imenter invited the child to drink some orange juice (Tesco brand, 'pure orange juice-made from concentrated orange juice'). A cup of orange juice was provided for the mother, and for the experimenter, and three cups of juice were available for the child. One of these contained Bitrex solution (at a concentration of 10 p.p.m.).

The entire experimental session was video-taped. The experimenter herself first took some juice, and invited the mother to try some of her own. The child was then encouraged to drink some juice. This was plain orange juice $(\mathrm{O})$. Following this, a cup containing a measured amount (100 gram) of orange juice to which Bitrex solution had been added (B) was substituted for the child's $O$, and the child was encouraged to take 'another drink'. The child's response after tasting this was noted, and the experimenter made an effort to get the child to indicate verbally how they found the Bitrex-added drink. The child was then invited to take some more from the B cup (a high proportion of children refused), and this was repeated until the child refused to take more. They were then invited to take more from their original cup, or from mother's cup. Finally, the experimenter offered the child a chocolate (chocolate has the effect of counteracting, to some extent, the bitter taste). The B cup was later weighed to measure the number of grams consumed.

From the videotapes, and the weighing of the B cups, the following variables were available:

(1) the number of times each child was prepared to taste $B$.

(2) the weight of Bitrex-added orange juice (B) consumed by each child.

(3) the child's verbal and non-verbal responses following the ingestion of Bitrexadded orange juice.

\section{RESULTS}

(1) The number of times each child was prepared to taste Bitrex-added orange juice (B). Of the 33 children tested, 30 took $B$ at least once. The remaining three are excluded from the rest of the analysis. Of the 30 who drank some of the B-added orange juice (B) 14 were boys and 16 girls. Of the 30 children who drank $B$, seven took it more than once.

Table 1. The number of times each child was prepared to taste Bitrex-added orange juice.

\begin{tabular}{lc}
\hline Number of B-drinks & Number of children \\
\hline 1 or more & 30 \\
2 or more & 7 \\
3 or more & 2 \\
4 & 1 \\
\hline
\end{tabular}

Eleven children also refused to take a further drink of the 'nice' (non-Bitrex) orange juice when it was offered (it was offered in 19 cases). 
(2) The weight of Bitrex-added orange juice (B) consumed by each child. The average consumption was 5.57 grams of $B$. Nine of the 30 children drank 4 grams, the modal amount, and one boy, who seemed 'immune' from the Bitrex effect, ingested 26 grams without a clear response.

Table 2. Frequencies of amount of Bitrex-added orange juice consumed by children in the sample.

\begin{tabular}{lc}
\hline Grams & Frequency \\
\hline$<1$ & 3 \\
2 & 5 \\
3 & 1 \\
4 & 9 \\
6 & 4 \\
8 & 2 \\
10 & 4 \\
12 & 1 \\
26 & 1 \\
Total & 30 \\
\hline Mean $=5.57 ;$ & Mode $=4 \cdot 0$
\end{tabular}

The difference between the amounts of $\mathrm{B}$ consumed by boys (mean $=6.42 \mathrm{gm} 8$ and girls (mean $=4.81 \mathrm{gm}$.) largely reflect the consumption of one boy and are nof. overall, significant. The correlation between intake and age $(r=.315)$ is also nọ significant.

(3) The child's verbal and non-verbal responses following the ingestion of Bitrex-added orange juice.

Behavioural responses to the ingestion of B were highly varied. There was no visible response in seven cases, although three of these children did refuse to take more B. Responses to initial ingestion (evident from the video information) are presented in Table 3.

Table 3. Children's responses to the initial ingestion of Bitrex-added orange juice.

\begin{tabular}{lr}
\hline no evident response & 7 cases \\
facial grimace & 17 cases \\
'shock'-rigidity or 'collapse' & 7 cases \\
pronounced mouth movements & 6 cases \\
noises, crying & 3 cases \\
retching, vomiting & 2 cases \\
\hline
\end{tabular}

(some children showed more than one response)

Although the latency of response was not measured precisely, it is clear from the $\stackrel{\overparen{\Phi}}{?}$ video evidence that a period of typically 3 or 4 often elapsed after drinking before it became apparent that the effect had registered with the child. 
A fuller analysis of each child's response pattern was made on the basis of repeated viewings of the videotapes. The following are some examples of the accounts derived from this method $\left({ }^{\prime} \mathrm{O}\right.$ ' = Orange juice; ' ${ }^{\prime}{ }^{\prime}=$ Orange juice with Bitrex; ' $E^{\prime}=$ Experimenter).

\section{Subject 2 - Carla (age 1.8; 10 grams B consumed)}

Child on mother's lap. Mother drinks $O$ and child eagerly takes some from same cup. B then offered. Drinks eagerly at first, then stops and lurches back. Pushes cup away (twice) with some force when offered again. Mouth movements evidents. $\mathrm{O}$ given to mother and child tries to prevent mother from taking it - twice. Child will not take B herself. When the cup is brought closer the child protects herself with her arm and starts crying. Takes a chocolate. Refuses $O$. Mother tries to drink $\mathrm{O}$ but child prevents this. Refuses a further offering, pushing cup away and shaking head.

\section{Subject 6 - Sophie (age 2.9; 4 grams B consumed)}

Child drawing. First mother takes some $\mathrm{O}$ and then child is persuaded to take $\mathrm{O}$. Finally takes B. After 2 or 3 seconds makes face, looks towards mother, then 'collapses' with head on table for 15s until persuaded to taste 'Mummy's drink'. Drinks more of the $\mathrm{O}$. Watches with great interest while $\mathrm{E}$ drinks $\mathrm{B}$, and agrees (with an 'Oh') when E pronounces drink 'nasty'. Takes a chocolate, and then another drink of $\mathrm{O}$.

\section{Subject $10-$ Kevin (age 2.0; 2 grams B consumed)}

On tasting B, shakes head and body. Refuses more drink offered, including mother's own juice, defending his mouth with his arm. Offered more juice but refuses. Backs away sharply when E brings cup towards his mouth. When E goes to get a chocolate, mother offers him a drink. Now he is perhaps less inhibited, and rapidly shuffles from one foot to the other in a brief but characteristic 'tantrum' movement. Eagerly accepts chocolate.

\section{Subject 18 - Jenny (age 2.2; 10 grams B consumed)}

E drinks, then child, and then mother. Mother draws, and then tells the child to take some of the B drink. The child takes some, then immediately turns away, looking somewhat disturbed, and pronounces it 'Yucky'. Chocolate is being brought but before it arrives the child vomits on the floor. After the mop-up operation she is assured that her mother's drink is a nice one, and immediately takes some of it.

\section{DISCUSSION}

With children of the age-range to be studied, it is impossible to adhere strictly to the standard testing procedure. The study was a naturalistic demonstration rather 
than a perfectly controlled experiment, and the experimenter was instructed to adapt her behaviour to the response style of the child and mother. Thus, children $\frac{\mathbb{\Phi}}{\mathbb{O}}$ who were clearly distressed after tasting the Bitrex-added juice were not unduly $\stackrel{\oplus}{a}$ pressured to repeat their experience.

Thus the objective measures derived from the study (weight of B consumed, $\stackrel{?}{\Rightarrow}$ number of repeated tastings of B) may not be the most important data available. $\stackrel{0}{\square}$ The main purpose of the study was to establish whether children do indeed find Bitrex-added orange juice distasteful, and to monitor their responses following the $\frac{\bar{\sigma}}{\bar{n}}$ ingestion of the liquid. It is clear that a large majority of the children found the Bitrex-added orange juice noxious. Most refused the offer of a second drink of this juice, and only two children of the 30 tested took a third drink. In most cases there was clear behavioural evidence of the children's distaste. This was most frequently evident in a facial grimace (17 cases) or pronounced mouth movements, but some children also showed pronounced whole-body reactions such as 'shock' or 'rigidity'. Some made noises and in the most extreme cases there was retching or vomiting. The children did not provide many spontaneous verbal descriptions of their experience, but they did tend to agree with the experimenter's prompt that the juice was 'Not very nice' and one 2-year old pronounced it 'Yucky'.

One child in the sample seemed totally immune to the noxious nature of $B$, and $\vec{z}$ if this finding were to be replicated in a larger sample it would suggest that less $\frac{\vec{m}}{3}$ than $5 \%$ of children would fail to receive some protection as a result of the addition of Bitrex to harmful household liquids. This figure might change con- $\vec{\varepsilon}$ siderably with the concentration of Bitrex, and with the particular solvent, as we as with the child's age, and with other circumstantial factors.

Therefore, the study clearly supports the view that when added to otherwis palatable substances Bitrex solution makes the substance profoundly unpalatable to most young children. It also adds considerable support to the hypothesis that the addition of Bitrex to dangerous household liquids is likely to considerably $\overrightarrow{\vec{O}}$ reduce the amount a child will ingest. Since many dangerous substances are 3 inherently noxious in their taste, adding Bitrex may increase their unpalatability still further and produce greater avoidance than was demonstrated when Bitrex was added to palatable orange juice. In the home situation, without the mother or $\stackrel{\oplus}{3}$ a stranger in attendance, the child might be less reticent about spitting the substance out.

It is not argued that the addition of Bitrex should replace the use of child $\stackrel{\rho}{\rho}$ resistant closures. This strategy has already proved effective, and in the U.K. and certain other countries regulations have been introduced to ensure that manufacturers produce 'safe' containers (Statutory Instruments, 1986). It does seem, likely, however, that the use of a bittering agent such as Bitrex may further increase the protection of children from accidental poisoning.

\section{REFERENCES}

Clarke A. W. \& Walton W. W. (1979) Effect of safety packaging on Aspirin ingestion by children. Pediatrics, 63, 687-693. 
Craft A. W., Lawson G. R., Williams H. \& Sibert J. R. (1984) Accidental childhood poisoning with household products. British Medical Journal, 288, 682.

Macfarlan Smith (1988) Bitrex - An Aversive Agent. Macfarlan Smith: Edinburgh.

Scherz R. G. (1970) Prevention of childhood poisoning. Pediatric Clinics of North America 17, 713.

Sibert J. R., Craft A. W. \& Jackson R. H. (1977) Child resistant packaging and accidental child poisoning. Lancet, ii, 289-90.

Statutory Instruments (1986, No. 758). Consumer Protection: The Child Resistant Packaging Safety Regulations. 